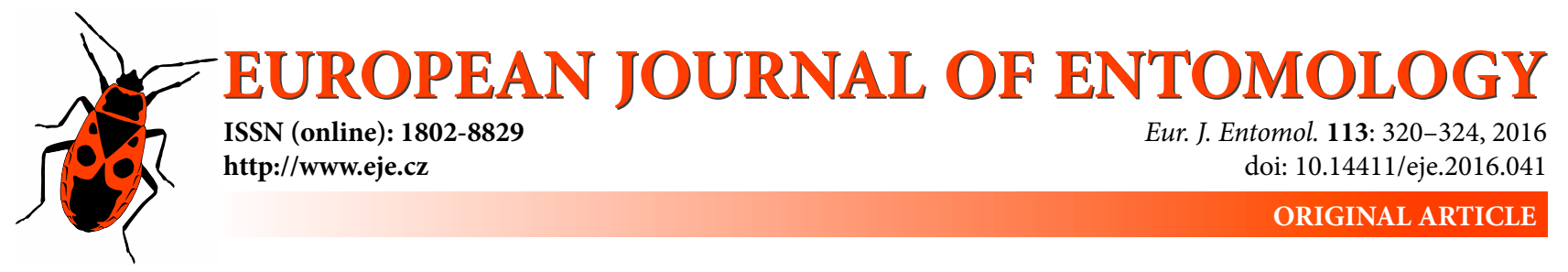

\title{
The cabbage moth or the sorrel moth (Lepidoptera: Noctuidae)?
}

\author{
Jefrerey A. HARVEY ${ }^{1,2}$, Eke HENGEVELD ${ }^{2}$ and Miriama MALCICKA ${ }^{1}$ \\ ${ }^{1}$ VU University Amsterdam, Department of Ecological Sciences, Section Animal Ecology, De Boelelaan 1085, 1081HV \\ Amsterdam, The Netherlands; e-mails: j.harvey@nioo.knaw.nl, m.malcicka@gmail.com \\ ${ }^{2}$ Netherlands Institute of Ecology, Department of Terrestrial Ecology, Droevendaalsesteeg 10, 6700 EH Wageningen, \\ The Netherlands; e-mail: E.Hengeveld@nioo.knaw.nl
}

Key words. Lepidoptera, Noctuidae, Mamestra brassicae, Brassica oleracea, cabbage, Rumex acetosa, development

\begin{abstract}
When insect herbivores develop over many generations on the same plant species, their descendants may evolve physiological adaptations that enable them to develop more successfully on that plant species than naïve conspecifics. Here, we compared development of wild and lab-reared caterpillars of the cabbage moth, Mamestra brassicae, on a cultivar of cabbage Brassica oleracea (cv. Cyrus) and on a wild plant species, sorrel, Rumex acetosa, on which the wild strain had been collected and reared for two earlier consecutive generations. The lab strain had been reared on the same cabbage cultivar for more than 20 years representing $>200$ generations. Survival to adult did not vary with strain or plant species. Both strains, however, developed significantly faster when reared on $R$. acetosa than $B$. oleracea. Pupae from the field strain were larger when reared on $B$. oleracea than on $R$. acetosa, whereas the identity of the plant species did not matter for the lab strain. Our results show that long-term rearing history on cabbage had little or no effect on $M$. brassicae performance, suggesting that some generalist herbivores can readily exploit novel plants that may be chemically very different from those on which they have long been intimately associated.
\end{abstract}

\section{INTRODUCTION}

In insect herbivores, dietary quality of the food plant represents a major constraint on growth, survival, development and fitness (Awmack \& Leather, 2002). Primary metabolites, such as nitrogen and amino acids, are important for insect growth although even the most nutritious plants often contain sub-optimal levels of these important metabolites (van Loon et al., 2005). Furthermore, most plants produce secondary metabolites which are often toxic and may thus hamper development and survival. Differing concentrations of primary and secondary metabolites in plants may have opposing effects on insect development, and these may be expressed in complex ways such as via root and shoot herbivory (Huang et al., 2013). Indirectly, plant quality may also affect herbivore survival by extending the duration of immature development, hence making herbivores more susceptible to natural enemies such as parasitoids and predators (the "slow-growth-high-mortality-hypothesis", Clancy \& Price, 1987; Benrey \& Denno, 1997).

The vast majority of insect herbivores are specialists, feeding on only a restricted number of plant species which contain phylogenetically-conserved secondary metabolites (Loxdale et al., 2011). This is the end-result of a long coevolutionary arms race involving plants and insect herbivores (Ehrlich \& Raven, 1964; Wheat et al., 2007). For instance, many butterfly species of the family Pieridae are limited to feeding on plants in the order Brassicales such as cabbages and mustards, that are characterized by their production of secondary plant metabolites called "glucosinolates" (Hopkins et al., 2009). These compounds are hydrolyzed into wide range of biologically active compounds, including isothiocyanates, which are toxic or repellent to many insect herbivores (Renwick, 2002; Hopkins et al., 2009). Other specialist insect herbivores in different families are also adapted to plants producing alkaloids, iridoid glycosides, and furanocoumarins (Wink 2003; Schoonhoven et al., 2005). The presence of these compounds is generally required to stimulate oviposition and/or feeding behaviour in the adult and larval stages respectively (Schoonhoven et al., 2005). It is known that specialist herbivores have evolved highly refined strategies to deal with the toxic effects of secondary plant metabolites. These strategies include detoxification, excretion and sequestration (Schoonhoven et al., 2005). In spite of this, specialist herbivores often become adapted to a small number of plant species in their own habitats.

Adaptation to interspecific variation in plant quality presents a different challenge for generalist herbivores, because successive generations of the same herbivore genotype or strain (and even the same individual within a single generation) may feed on different plant species that have completely unique secondary metabolites (Bernays 
\& Minkenberg, 1997; Singer et al., 2002). For this reason generalists have often evolved different strategies to deal with plant toxins than specialists; the latter are also generally better adapted at dealing with specific kinds of allelochemicals produced by plants on which they have evolved (Reudler et al., 2011). One means with which generalists are able to cope with plant toxins over time is through longterm adaptation to the same plant species or related plants with phylogenetically conserved secondary metabolites (Thöming et al., 2013). In this scenario, the mother tends to lay eggs on the plant on which she developed, and so on over the course of many generations. Adaptation to plants in this situation has recently been referred to as "composite generalization" (Hägele \& Rowell-Rahier, 1999; Singer, 2001) and is the first evolutionary step towards reproductive isolation, dietary specialization and potential speciation in a generalist herbivore (Loxdale et al., 2011; Loxdale \& Harvey, 2016).

In this study we compare and contrast development of two strains of the cabbage moth, Mamestra brassicae (L.) (Lepidoptera: Noctuidae) when developing on a cultivated plant, Brassica oleracea (L.), and an unrelated wild species, the sorrel, Rumex acetosa (L). Both plants are phylogenetically unrelated and possess very different specialized secondary metabolites that have evolved to repel herbivores and/or pathogens. Cultivated cabbage is derived from wild ancestors that grow naturally along the coastlines of northwestern Europe (Mitchell \& Richards, 1979). Wild cabbage populations exhibit significant genetic variation in the expression of glucosinolates (GS) at relatively small spatial scales (Gols et al., 2008). Cultivated cabbages have generally been bred to reduce concentrations of GS, making these plants highly susceptible to attack from both generalist and specialist insect herbivores (Gols et al., 2008; Chen et al., 2015). Sorrel is a widespread plant that is native to Eurasia (Korpelainen, 1992) and is characterized by the production of flavonoids, tannins, flavone C-glycosides and flavonol O-glycosides (Kato \& Morita, 1990) although the biological effects of these compounds on insects and pathogens has as far as we know not yet been studied.

A wild strain of $M$. brassicae was collected as eggs from leaves of $R$. acestosa plants in the field and then reared for two successive generations on the plant; the other strain was originally collected from cultivated cabbage plants in the early 1990s and has been subsequently reared continually on the same plant for over 20 years, representing a minimum of more than 200 consecutive generations on cabbage. Both strains are based on large numbers of individual insects. The two plant species studied here are perennials and individual plants may live up to several years in the field, although cultivated cabbages are generally only allowed to grow for a single growing season. Here, different fitness correlates of the two strains were compared and contrasted when reared on the two plants. Larval survival, development time to pupation and pupal mass were measured in the two M. brassicae strains on the two plant species. The main hypotheses were (1) M. brassicae from the lab strain will develop better on cabbage (on which it has a rearing history) than on $R$. acetosa, and (2) M. brassicae from the field strain will perform equally well on the two plant species, owing in part to the recognized high quality of $B$. oleracea as a food plant for this herbivore, and because the longer term developmental history of this strain is unknown.

\section{MATERIALS AND METHODS}

\section{Plants}

Cabbage plants were grown in greenhouse facilities at Unifarm adjacent to Wageningen University (WU). Three-week old plants were transferred to the Netherlands Institute of Ecology (NIOO) and grown in greenhouses with supplemented light (halide lamps) at $23 \pm 2{ }^{\circ} \mathrm{C}$ (day) and $16 \pm 2{ }^{\circ} \mathrm{C}$ (night) with a $16 \mathrm{~L}: 8 \mathrm{D}$ regime. Nutrient solution was added to the plants twice per week. $R$. acetosa plants were grown from seeds collected close to NIOO, under the same conditions as the cabbage plants. All plants of both species were 5-6 weeks old when used in experiments. Both plants were used in these experiments when they were in early stages of development but when they had attained a significant proportion of their leaves and were approaching maximum mass.

\section{Insects}

The cabbage moth, M. brassicae is a so-called generalist (= polyphagous) species and feeds on many herbaceous plants in nature. The species is univoltine. Female moths typically lay batches of eggs on plants in early to mid-summer. Newly hatched caterpillars are very motile and rapidly disperse at hatching to feed and whilst they may feed on the natal plant, many will leave this and feed on taxonomically unrelated neighbouring plants. The larvae complete five instars and at maturity abandon the food plant and burrow into the soil where they pupate. The pupae overwinter in the soil and adult moths emerge late the following spring.

$M$. brassicae from the lab strain were originally collected in cabbage fields in Wageningen, The Netherlands in the early 1990s. Thereafter they have been exclusively reared on cabbage (cv. Cyrus) for more than 20 years. Male and female moths were placed in groups of approximately ten (five of each sex) into plastic flasks containing a vermiculite base and $20 \%$ sugar solution absorbed into cotton wool in a small plastic vial. Blotting paper was placed around the inside of the flask and as a lid secured by an elastic band. The females lay batches of eggs directly onto the paper. Newly hatched larvae were placed in large aluminium rearing cages $(40 \times 40 \times 60 \mathrm{~cm})$ containing t cabbage plants. New plants were added as necessary. Pre-pupae were collected from the cages and placed in plastic boxes $(25 \times 10 \times 10 \mathrm{~cm})$ containing a layer of vermiculite into which they pupate.

The field strain of M. brassicae was collected as large egg batches (>100 eggs) from leaves of $R$. acetosa in Wageningen, The Netherlands, in August, 2013. They were reared the same way as the lab strain for one generation on $R$. acetosa. The second generation was then used for experiments on the two food plant species.

\section{Development of $M$. brassicae on Rumex acetosa and Brassica oleracea}

Eggs of M. brassicae were collected on cabbage plants and sorrel plants from the two strains that had been reared separately. Upon hatching, for each plant species (hence ten for each strain) approximately 100 neonate larvae were placed into five separate plastic boxes $(18 \times 10 \times 10 \mathrm{~cm})$ containing excised leaves of either $R$. acetosa or B. oleracea (based on where caterpillars hatched). Excised leaves were used because $1^{\text {st }}$ instar larvae are tiny and easier to track during the first instar when they are in closed containers. The larvae were developed on these excised 
leaves until they were in the late first (L1) instar; at this stage they were placed in groups of 20 in cages containing either four cabbage or four sorrel plants. For each strain/plant treatment five cages were used. The larvae were allowed to feed and move about on the plants. Fresh plants were provided as necessary to ensure that food supply for larval development was not limiting. Prepupae were collected and placed in plastic boxes according to cage number and food plant (as described above) until pupation. Fresh pupae were weighed on a Mettler Microbalance (accuracy $1 \mu \mathrm{g}$ ). Development time was determined as the number of days between hatching and pupation; survival was determined as the percentage of larvae (out of 20 per cage) that successfully pupated.

\section{Statistical analyses}

All statistics were performed on MINITAB (State College, PA, USA) program number 16 .

Data on development time and pupal mass were analysed using two-way ANOVAs with plant species and herbivore strain as factors, with five cages per treatment as units of replication. For survival the number of larvae surviving per cage and treatment was determined and the resulting data sets analysed per cage using ANOVA. Multiple ad hoc comparisons were made using TukeyKramer tests. All data was normally distributed and thus transformations were not required.

\section{RESULTS}

\section{Survival, development time and pupal mass of wild and lab strains of Mamestra brassicae on Rumex acetosa and Brassica oleracea}

Survival of $M$. brassicae to the adult stage did not vary significantly with herbivore strain $\left(F_{1,16}=2.63, P=0.124\right)$ nor with plant species $\left(F_{1,16}=0.81, P=0.381\right)$. The interactive effect on these parameters was also not significant $\left(F_{1,16}=0.03, P=0.859\right)$. Both plants were of high suitability for $M$. brassicae development, with $>75 \%$ of all caged caterpillars successfully pupating (Fig. 1A).

There was, however, a highly significant difference in larval-pupal development time between the two strains of $M$. brassicae when developing on $R$. acetosa and $B$. oleracea plants respectively $\left(F_{1,322}=274.39, P<0.0001\right)$. Furthermore development time varied significantly in both strains of $M$. brassicae on the two food plant species $\left(F_{1,322}\right.$ $=803.71, P<0.0001)$, although this parameter did not differ significantly amongst individual caterpillars developing in different cages $\left(F_{4,322}=1.31, P=0.0264\right)$. Interactive effects were significant for strain/cage $\left(F_{4,322}=7.51, P<\right.$ $0.0001)$ and strain/plant $\left(F_{1,322}=40.18, P<0.0001\right)$ but not for cage/plant $\left(F_{4,322}=2.20, P=0.068\right)$. Most notably, caterpillars of both $M$. brassicae strains developed much more rapidly when reared on sorrel than on cabbage plants (Fig. 1B). The difference was greater in the lab strain, which took almost 4 additional days on average to pupate when developing on $B$. oleracea compared with $R$. acestosa.

Pupal mass of $M$. brassicae also varied significantly with herbivore strain $\left(F_{1,322}=8.68, P<0.01\right)$ plant species $\left(F_{1,322}\right.$ $=21.71, P<0.0001)$ and cage $\left(F_{4,322}=10.57, P<0.0001\right)$. There were also significant interactive effects between herbivore strain and plant $\left(F_{1,322}=9.48, P<0.01\right)$ and cage and plant $\left(F_{4,322}=2.58, P=0.037\right)$. The interaction between strain and cage was not significant $\left(F_{4,322}=0.88\right.$,

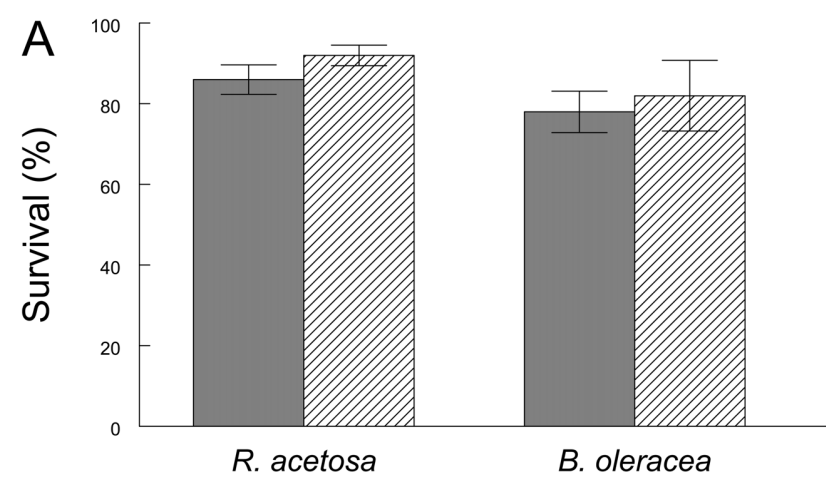

Plant species

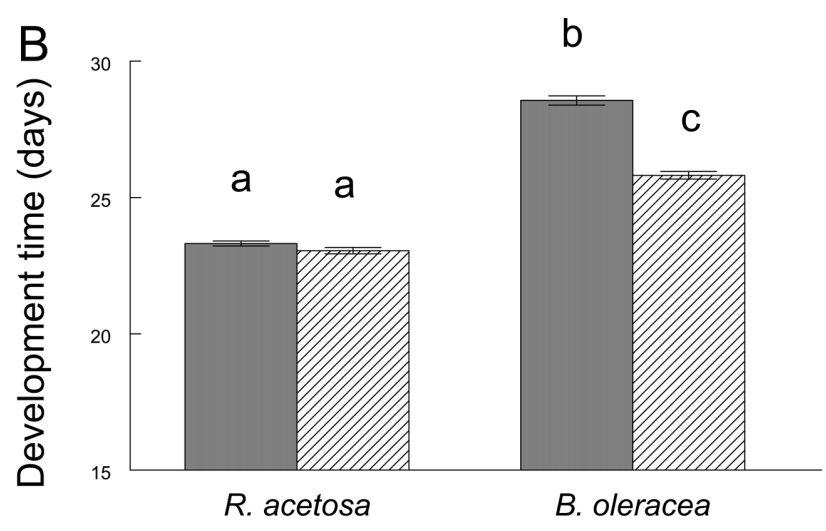

Plant species

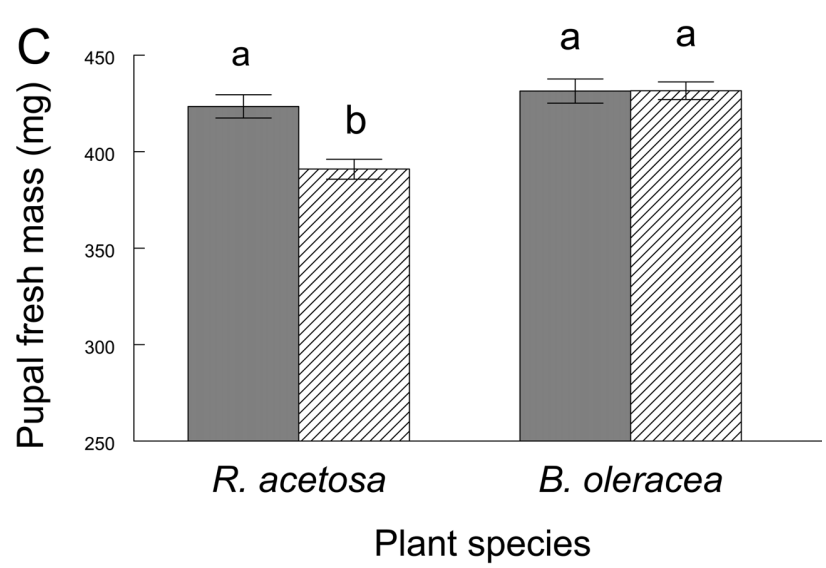

Fig. 1. Fitness correlates of the cabbage moth, Mamestra brassicae, originating from a wild strain (collected in 2013 as eggs from Rumex acetosa) and a laboratory strain (collected on cultivated cabbage (Brassica oleracea) in the early 1990s and reared consecutively on this plant for over 20 years and $200+$ generations). A - egg-to-adult survival; B - larval-pupal development time; C pupal fresh mass. Line bars represent standard error of the mean. Gray bars $=$ laboratory strain and hatched bars $=$ field strain. Bars with the same letters are not significantly different $(P>0.05$, TukeyKramer tests). Sample sizes are: $B$. oleracea laboratory $-M$. brassicae $=78 ; B$. oleracea field $-M$. brassicae $=82 ; R$. acetosa laboratory $-M$. brassicae $=86 ; R$. acetosa field $-M$. brassicae $=92$.

$P=0.474$ ). Pupae of the field strain were slightly smaller when reared on the natal plant (sorrel) whereas other pupal masses of the two strains on the two plant species were approximately similar (Fig. 1C). 


\section{DISCUSSION AND CONCLUSIONS}

Like many generalist herbivores, neonate larvae of $M$. brassicae rapidly disperse at hatching and the caterpillars may therefore feed on plants other than the natal plant on which the mother oviposited (J.A. Harvey, pers. observ.). In nature, $M$. brassicae is also known to feed on a wide range of plant species with very different secondary metabolites (Robinson et al., 2010). The domesticated strain of M. brassicae used here had, however, been reared for many consecutive generations on a cabbage cultivar. Despite this, it developed to the pupal stage significantly faster (almost 4 days) when reared exclusively on leaves of a wild plant, $R$. acetosa, than on cabbage. Moreover, we unexpectedly found that pupal mass of the field strain was smaller when reared on $R$. acetosa, whereas pupae of the laboratory strain were of equal mass on both food plants.

These results shed interesting light on important aspects of development related aspects of plant-herbivore interactions. For instance, at least in the lepidopteran species $M$. brassicae and strains studied here, a long-term association with a plant species (cabbage) had little effect in making that plant of higher quality in terms of development time compared with an unrelated wild plant species. Long-term adaptation represents an important foundation of evolutionary theory in plant-herbivore interactions (Via, 1990). In this scenario, repeated exposure to a plant over the course of many generations physiologically "conditions" a herbivore strain or genotype to that plant species, enabling it to outcompete conspecifics which are physiologically naïve to the plant (Witham \& Slobodchikoff, 1981; Strauss \& Karban, 1994; Egan \& Ott, 2007). In our study, the lab strain of $M$. brassicae developed much faster on $R$. acestosa without any negative effect on pupal mass, even though it had been continually reared on cabbage for over 20 years and approximately 200 generations (given that it completes $\sim 10$ generations a year under lab conditions). The lab strain had originally been collected on leaves of cultivated cabbages, and it had not been replenished with fresh field material at all in the intervening decades.

Cultivated cabbage and related domesticated plants (e.g. B. napus) have long been considered as the main food plants of $M$. brassicae, hence its name, the "cabbage moth". Crops derived from wild cabbages (e.g. Brussel's sprout, white cabbage, red cabbage, cauliflower) are grown over most of the world in large scale agriculture. Even so, wild cabbage is, however, not a naturally occurring plant over most of continental Europe, revealing that M. brassicae must be well adapted to exploit other wild plants with which it may have co-evolved over a long period of time and where cabbage cultivars are absent. Wild cabbages are native and restricted to the coastlines of Europe, including the British Isles, France and Spain (Lanner-Herrera et al., 1996). Recent lab studies have shown that, while some wild cabbage populations are suitable for the development of M. brassicae, others are not (Gols et al., 2008; Harvey \& Gols, 2011).

Mamestra brassicae is a generalist herbivore that, along with several other generalist noctuid herbivores, deals with ingested plant toxins by metabolizing at least a proportion of the ingested allelochemicals (Schramm et al., 2012). It is an unusual herbivore in that it is capable of dealing with toxins from plants that are highly toxic to both related generalist (e.g. Noctuidae) and unrelated specialist herbivores. For instance, the warty cabbage, Bunias orientalis (L.), is a large, brassicaceous plant native to western Asia that has recently become an abundant invader in parts of Europe over the past 30 years (Dietz et al., 1999). The plant is toxic to most herbivores, including other generalist noctuids and several brassicaceous specialists including the larvae of cabbage butterflies (Pieris spp.) and the diamondback moth, Plutella xylostella (Harvey et al., 2010; Fortuna et al., 2012). By contrast, M. brassicae performs very well on this plant (Harvey et al., 2010) and large numbers of its larvae have been found on B. orientalis in Germany (J.A. Harvey, pers. observ.) .

In summary, a laboratory strain of $M$. brassicae developed better on a wild plant ( $R$. acetosa) despite being intimately associated with a laboratory strain of cabbage (B. oleracea) for many years. These results, at least in the context of this herbivore species and its plant associations challenge previous work (e.g. Schoonhoven \& Meerman, 1978) as well as existing theory in terms of long-term adaptation. We argue that the outcomes of these interactions are likely to be association-specific and to reflect various ecophysiological aspects of the species under investigation, but at the same time we caution against making overly broad generalizations. It is envisaged that further research incorporating a wider spectrum of plant types as well as other herbivores will shed more light on the validity of long-term adaptation in generalist and perhaps even specialist insect herbivores as well.

ACKNOWLEDGEMENTS. The authors would like to thank L. Westerd and colleagues at Wageningen University for supplying eggs of Mamestra brassicae, and G. Disveld for providing phytotron facilities.

\section{REFERENCES}

Awmack C.S. \& Leather S.R. 2002: Host plant quality and fecundity in herbivorous insects. - Annu. Rev. Entomol. 47: 817-844.

BenRey B. \& Denno R.F. 1997: The slow-growth-high-mortality hypothesis: a test using the cabbage butterfly. - Ecology $\mathbf{7 8}$ : 987-999.

Bernays E.A. \& Minkenberg O.P.J.M. 1997: Insect herbivores: different reasons for being a generalist. — Ecology 78: 11571169.

Chen Y.H., Gols R. \& Benrey B. 2015: Crop domestication and its impact on naturally selected trophic interactions. - Annu. Rev. Entomol. 60: 35-58.

Clancy K.M. \& Price P.W. 1987: Rapid herbivore growth enhances enemy attack: sublethal plant defenses remain a paradox. - Ecology 68: 733-737.

Dietz H., Fischer M. \& SCHMid B. 1999: Demographic and genetic invasion history of a 9-year-old roadside population of $\mathrm{Bu}$ nias orientalis L. (Brassicaceae). — Oecologia 120: 225-234.

Egan S.P. \& Otт J.R. 2007: Host plant quality and local adaptation determine the distribution of a gall-forming herbivore. Ecology 88: 2868-2879. 
EHRLICH P.R. \& RAVEN P.H. 1964: Butterflies and plants: a study in coevolution. - Evolution 18: 586-608.

Fortuna T.M., Vet L.E.M \& Harvey J.A. 2012: Effects of an invasive plant on the performance of two parasitoids with different host exploitation strategies. - Biol. Contr. 62: 213-220.

Gols R., Bukovinszky T., Van Dam N.M., Dicke M., Bullock J.M. \& Harvey J.A. 2008: Performance of generalist and specialist herbivores and their endoparasitoids differs on cultivated and wild Brassica populations. - J. Chem. Ecol. 34: 132-143.

HÄGEle B.F. \& Rowell-RAhIER M. 1999: Choice, performance and heritability of performance of specialist and generalist insect herbivores towards cacalol and seneciphylline, two allelochemicals of Adenostyles alpina (Asteraceae). - J. Evol. Biol. 13: 131-142.

HaRvey J.A. \& Gols R. 2011: Population-related variation in plant defense more strongly affects survival of an herbivore than its solitary parasitoid wasp. - J. Chem. Ecol. 37: 10811090

Harvey J.A., Biere A., Fortuna T., Vet L.E.M., Engelkes T., Morrien E., Gols R., Verhoeven K.J.F., Vogel H. \& Van Der Putten W.H. 2010: Ecological fits, mis-fits and lotteries involving insect herbivores on the invasive plant, Bunias orientalis. - Biol. Invas. 12: 3045-3059.

HopKInS R.J., VAN DAM N.M. \& VAN LoON J.J.M. 2009: Role of glucosinolates in insect-plant relationships and multitrophic interactions. - Annu. Rev. Entomol. 54: 57-83.

Huang W., Siemann E., Yang X.F., Wheeler G.S. \& Ding J.Q. 2013: Facilitation and inhibition: changes in plant nitrogen and secondary metabolites mediate interactions between aboveground and below-ground herbivores. - Proc. R. Soc. (B) 280: 20131318, $7 \mathrm{pp}$.

Kato T. \& Morita Y. 1990: C-Glycosylflavones with acetyl substitution from Rumex acetosa L. - Chem. Pharm. Bull. 38 : 2277-2280

Korpelainen H. 1992: Patterns of resource allocation in male and female plants of Rumex acetosa and R. acetosella. - Oecologia 89: 133-139.

Lanner-Herrera C., Gustafeson M., Filt A.S. \& Bryngelsson T. 1996: Diversity in natural populations of wild Brassica ol eracea as estimated by isozyme and RAPD analysis. - Genet. Resour. Crop Evol. 43: 13-23.

Loxdale H.D., Lushai G. \& HaRvey J.A. 2011: The evolutionary improbability of 'generalism' in nature, with special reference to insects. - Biol. J. Linn. Soc. 103: 1-18.

Loxdale H.D. \& Harvey J.A. 2016: The 'generalism' debate: misinterpreting the term in the empirical literature focusing on dietary breadth in insects. - Biol. J. Linn. Soc. [in press].

Mitchell N.D. \& Richards A.J. 1979: Biological flora of the British Isles. No. 145. Brassica oleracea L. ssp. oleracea. - J. Ecol. 67:1087-1096.

Renwick J.A.A. 2002: The chemical world of crucivores: lures, treats and traps. - Entomol. Exp. Appl. 104: 35-42.
Reudler J.H., Biere A., Harvey J.A. \& Van Nouhuys S. 2011: Differential performance of a specialist and two generalist herbivores and their parasitoids on Plantago lanceolata. $-J$. Chem. Ecol. 37: 765-778.

Robinson G.S., Ackery P.R., Kitching I.J., Beccaloni G.W. \& Hernandez L.M. 2010: HOSTS: A Database of the World's Lepidopteran Hostplants. Natural History Museum, URL: http://www.nhm.ac.uk/our-science/data/hostplants/

Schoonhoven L.M. \& MeERman J. 1978: Metabolic cost of changes in diet and neutralization of allelochemics. - Entomol. Exp. Appl. 24: 689-693.

Schoonhoven L.M., Van Loon J.J.M. \& Dicke M. 2005: InsectPlant Biology. Oxford University Press, Oxford, 448 pp.

Schramm K., Vassao D.G., Reichelt M., Gershenzon J. \& Wiттsтоск U. 2012: Metabolism of glucosinolate-derived isothiocyanates to glutathione conjugates in generalist lepidopteran herbivores. - Insect Biochem. Mol. Biol. 42: 174-182.

SINGER M.S. 2001: Determinants of polyphagy by a woolly bear caterpillar: a test of the physiological efficiency hypothesis. Oikos 93: 194-204.

Singer M.S., Bernays E.A. \& Carriere Y. 2002: The interplay between nutrient balancing and toxin dilution in foraging by a generalist insect herbivore. - Anim. Behav. 64: 629-643.

StRAuss S.Y. \& Karban R. 1994: The significance of outcrossing in an intimate plant-herbivore relationship. I. Does outcrossing provide an escape form herbivores adapted to the parent plant? - Evolution 48: 454-464.

Thöming G., Larsson M.C., Hansson B.S. \& Anderson P. 2013: Comparison of plant preference hierarchies of male and female moths and the impact of larval rearing hosts. - Ecology 94 : 1744-1752.

Van Loon J.J.A., Casas J. \& Pincebourde S. 2005: Nutritional ecology of plant-insect interactions: persistent handicaps and the need for innovative approaches. - Oikos 108: 194-201.

VIA S. 1990: Ecological genetics and host adaptation in herbivorous insects: the experimental study of evolution in natural and agricultural systems. - Annu. Rev. Entomol. 35: 421-446.

WINK M. 2003: Evolution of secondary metabolites from an ecological and molecular phylogenetic perspective. - Phytochemistry 64: 3-19.

Wheat C.W., Vogel H., Wittstock U., Braby M.F., Underwood D. \& Mitchell-Olds T.M. 2007: The genetic basis of a plantinsect coevolutionary key innovation. - Proc. Natl. Acad. Sci. U.S.A. 104: 20427-20431.

Whitham T.G. \& SLobodchiKoff C.N. 1981: Evolution by individuals, plant-herbivore interactions, and mosaics of genetic variability: the adaptive significance of somatic mutations in plants. - Oecologia 49: 287-292.

Received January 15, 2016; revised and accepted March 29, 2016 Published online April 21, 2016 